\title{
UN ESCRITOR GRIEGO FUERA DE EUROPA
}

\author{
Roberto Quiroz Pizarro \\ Universidad de Chile. Chile
}

Resumen: Este trabajo contribuye a establecer una perspectiva histórica de la singular línea de aparición que fue teniendo la obra del escritor griego fuera de Europa. Se destacan algunos episodios que tienen que ver con sus obras traducidas y Sudamérica.

Palabras claves: Nikos Kazantzakis, Heleni Samíu, Panaït Istrati, Kimon Friar, Carlos Lohlé, Miguel Castillo Didier, traducción, traductores, ediciones, editores, Europa, Sudamérica, Odisea

\section{A GREEK WRITER OUTSIDE EUROPE}

Abstract: This article is a contribution to the establishing of a historical perspective of the singular line of appearance which the work of the Greek Writer had outside Europe. Several episodes which are related to the translations of his works and South America are highlighted.

Key words: Nikos Kazantzakis, Heleni Samiu, Panait Istrati, Kimon Friar, Carlos Lohlé, Miguel Castillo Dididier, translation, translators, editions, editors, Europe, South America, Odyssey.

\section{Recibido: 18.12.08 - Aceptado: 19.03.09}

Correspondencia: Roberto Quiroz P. (alfanamaste@hotmail.com) Licenciado y Magíster en Filosofía, Universidad de Chile. Doctorado(C) Universitat Jaume IValencià. Profesor y Subdirector del Centro de Estudios Griegos Bizantinos y Neohelénicos, Universidad de Chile. 


\section{Roberto Quiroz P.: Un escritor griego fuera de Europa}

A pesar de las opiniones dispares esgrimidas y de las críticas que se formulan en torno al cuestionado "arte de la traducción"-diferenciándolo así del proceder formalista de la ciencia moderna--, vemos que lo empíricamente predominante en tales territorios sigue siendo la vigencia de ese arte --por sobre otros caminos-- para acercarse a los horizontes de la literatura. Al respecto, hacemos la premeditada pregunta de cuántos pueden darse el lujo de leer a Homero, Goethe, Shakespeare, Dostoievsky, Malraux, Papini, Tagore, por ejemplo, en sus lenguas vernáculas. No es la mayoría, de eso podemos estar seguros.

A simple vista y en virtud de la anterior pregunta dejada al camino, resulta entonces que la traducción -nos guste o no--, vuelve a ser el medio del que disponemos para darle luz a los textos que provienen de otras lenguas y de otras latitudes.

Las críticas en cuestión se basan en esa especie de "distancia no mensurable" -un abismo semántico-- entre lo que sería el texto original intacto y el resultado a que se llega mediante esa plasmación que recae en el cuerpo vivo de otra lengua. La vieja polémica del "traduttore traditore".

En el día a día de nuestra cultura cotidiana y de todo lo que tenemos por tarea de lecturas, lo más cierto es que vamos leyendo obras traducidas a nuestra lengua de nacimiento, y lo hacemos a pesar de que los círculos literarios defiendan cada literatura en su idioma nativo. Sin embargo, pese a las resistencias, la traducción sigue en competencia como mecanismo mejorable en el tiempo, e incluso, se llega a decir de ella que es el "órganon" transmisor per excellentiam y que nos permite llegar a donde seguramente no llegaríamos: ella abre las fronteras de nuestra lengua madre y es puente hacia otras latitudes de lenguaje. En fin, obras traducidas son las que nos ponen en contacto con otros mundos y culturas que no son los de nuestro inmediato entorno.

Más allá de estas polémicas viejas y nuevas, dejamos a la vista que el objetivo de este trabajo no transita por la teoría literaria ni en sopesar las traducciones bajo criterios de valoración en favor o en contra. Al contrario, es a partir de las propias traducciones de la obra de Nikos Kazantzakis en América del Sur --y en un caso particular de circunstancias--, por donde quisiéramos navegar y dar una mirada cercana a las vicisitudes que han acompañado y han puesto un sello de relevancia en la llegada y recepción de ese corpus literario. Nada más buscamos en el pasado lo que ahora nos parece tan cercano, tan digno de conocer como son las emboscadas literarias que forjaron un lugar para Kazantzakis en el corazón de América.

La ruta del trabajo elegido no es la confección de un listado pormenorizado de todas las traducciones o versiones que existen de sus libros y que hayan o que estén circulando por América Hispana ${ }^{1}$. Lo necesario en el camino elegido no es tal $-u n$

${ }^{1}$ Para el lector interesado en obtener un detallado panorama de la obra de Kazantzakis y su circulación en Sudamérica, remitos al libro Nikos Kazantzakis: su Cronología, 
Byzantion Nea Hellás 28, 2009: 207-234

escritor griego fuera del Viejo Mundo--, sino que como todo misterioso comienzo lo que nos interesa es intuir la magnitud de un fenómeno literario que fue haciendo presión y emergiendo en estas latitudes amerindias.

\section{Primeras noticias}

El caso de la llegada de las primeras traducciones de Kazantzakis a tierras de Sudamérica ilustra, claramente, lo que sería un ejemplo de lo que podríamos metaforear como de salvataje intelectual, porque se trataba de una obra que si no se la hubiera traducido, posiblemente, se hubiese perdido para el Nuevo Mundo: un populoso continente de lectores no hubiera contado con un fácil acceso a las obras no traducidas de Kazantzakis, obras que vienen espigadas con el esplendor de una lengua de 3.500 años en el tiempo --obviamente que Kazantzakis no escribió como Homero o las Anacreónticas pero su lengua está entretejida por una misma sangre cultural que continua viva.

En este panorama especial, el de América Latina, el papel de la traducción abrió el contacto necesario y posible entre dos mundos tan distantes, lo cual si se aprecia bajo la dimensión de los estudiosos, interesados y publico lector en general, significa que estamos aludiendo a la condición de ser ni más ni menos que una de las así llamadas lenguas mayoritarias en el mundo. Una de las tantas, por supuesto, no la única.

La barrera de las lenguas o la misteriosa torre de Babel que hemos oído contar, no impidieron que Kazantzakis sin ser todavía un autor tan conocido en el concierto europeo y en la España de la guerra civil, pudiera ser descubierto aquí, años antes que en otras partes, mediante la traducción de sus obras que se escribiesen en francés. Fue el extraño caso de Sudamérica.

Haciendo un poco de historia sabemos que alrededor de los años treinta el autor griego comienza a figurar precozmente en los escaparates del mundo literario europeo. Por ese tiempo, del año 30 en adelante, el escritor griego viajará muchísimo dentro de Europa y de su país, aprendiendo, escribiendo, desarrollando una serie de actividades intelectuales diversas, entre las que cabe mencionar la idea de una historia de la literatura rusa, la preparación de un diccionario greco-francés, la traducción de la Divina Comedia, la redacción de sus impresiones por España que las publica un periódico ateniense Kathimeriní; una Antología de poetas españoles contemporáneos que se publica en la revista Kíklos y también algunos textos escolares que ven la luz a mediados de la misma década.

En 1935, el periódico Acrópolis publica sus impresiones sobre el Lejano Oriente. En cuanto a sus obras más reconocidas, algunas se difunden, como por ejemplo, Toda-Raba que se publica en 1931 en la Revue des Vivants de París y que más tarde, sólo dos años después, se reedita en la revista Le Cahier Bleu. Durante los

Bibliografia Castellana e Iconografia poética de Roberto Quiroz. Ed. Centro de Estudios Griegos Bizantinos y Neohelénicos, Santiago, 1997. 


\section{Roberto Quiroz P.: Un escritor griego fuera de Europa}

primeros meses de 1936 Kazantzakis escribe El jardín de rocas en francés, el que será editado tres años después en Holanda, en la revista Weteldbibliotheck. A fines de 1938 sale publicado su libro de Viajes Japón-China. Recién al año siguiente, 1939, una importante revista literaria griega, Nea Hestía, publicará la tragedia Melisa. Otra de sus tragedias con tema nacional, Nicéforo Focás, publicada a fines de 1927, alcanza 12 años después una segunda edición.

Tal es el panorama aproximado de las obras que pudieron ser publicadas por alguna revista o periódico interesado dentro de esos 10 años de viajes, entre 1930 y 1940. Si nos atenemos al cuadro anterior, entonces, se estará de acuerdo en que aún por estos años estamos en la antesala del reconocimiento mundial que más tarde será unánime. Mientras tanto, en medio de ese aparente silencio, es que ha de suceder que un desconocido escritor griego irrumpirá con llamativas luces en el medio editorial nacional chileno, lo cual para nosotros continúa siendo todo un misterio en la actualidad. El hecho como tal significa más que la simple circulación de la obra de un escritor que se estaba haciendo conocido, que se destacaba, sino que conlleva la traducción y la publicación de Kazantzakis por una casa editorial chilena, algo que para el momento parecía toda una aventura impensada. Entonces, la primera deducción a la vista de tal hecho es que gracias a la traducción -cuestionable en sí o tolerable--, todo un mundo lejano como el de Grecia pudo desembarcar en las riberas literarias del extremo sur.

Después de la Segunda Guerra Mundial, a mediados de los cuarenta, es cuando se multiplicarán en Europa las ediciones de sus novelas más célebres, Vida y hechos de Alexis Zorbás y Cristo de nuevo crucificado. En América Hispana, las ediciones comenzarán casi diez años después, en 1954. Sin embargo, lo llamativo de esto para la trayectoria de Nikos Kazantzakis en Sudamérica es lo que hemos señalado anteriormente, que se le mencione muchos años antes, cuando pocos fuera de Grecia sabían de él.

Testimonio directo de este contexto del que estamos haciendo alusión, aproximadamente de unos 72 años de historia hacia atrás, es sobre el cual tenemos la suerte de conservar una diminuta nota editorial publicada en una revista de la época llamada Ercilla y que hasta hoy circula en Chile. Aún cuando sea breve el comentario de la publicación en cuestión, el texto en su totalidad contiene detalles muy interesantes que le facilitan al público lector de ese entonces un panorama de quien sea ese nuevo escritor que ha emergido. La nota de Ercilla condensa en muy pocas líneas un nutrido manojo de detalles -ciertos y erráticos, valga decir--, razón por la cual resulta sorprendente de imaginar que justo por esa época se hablara de un tal Nikos Kazantzakis aquí, en Santiago de Chile.

Todo el fragmento es interesante, desde el entusiasmo con que se publicita la aparición de un nuevo escritor, comparándoselo con Malraux y Panait Istrati, o en el momento en que se le llama con un nombre actualmente inusual. Lo más llamativo es cuando nos damos cuenta de la increíble novedad de que en un país tan lejano de la eterna Grecia, una revista nacional tiene noticias de que existe un escritor a orillas de 
Europa que desarrolla una magistral obra que se llama Odisea. Esta debe ser una de las primeras menciones sobre dicha obra en el mundo.

Como hemos mencionado, sus pocas traducciones datan de varios años después. Por tanto, si nos retrotraemos a la original escena literaria de aquel entonces, al viejo Chile republicano de los años 30, un manifiesto asombro y emoción lejana reaparecen ante los ojos, pues nos hacemos una idea imaginaria del camino insólito que fueron tomando algunas traducciones de Kazantzakis fuera de su tierra y de su lengua.

Bajo la anterior circunstancia nos detenemos a releer ese pequeño texto de Ercilla, el que como hemos señalado, es de valor histórico.

La fecha corresponde al 30 de mayo de 1937, a momentos no lejanos de cuando el mundo estaría próximo a precipitarse en peligrosas heridas humanas. Reproducimos el texto íntegro tal cual aparece, sin alteraciones:

\section{“Acezante y pugnaz, ha surgido en Grecia un nuevo Malraux: Nicolás Kazán}

Así puede calificarse a Nicola Kazantzaki -Nicolás Kazán-autor de Toda-Raba: nuevo Malraux Las páginas de este libro están escritas con ese modo acezante y pugnaz que es característico del autor de "Los conquistadores" y "La condición humana", mucho más que el de "Tiempo del desprecio". Nicolás Kazán ha viajado por Rusia y Asia Menor. Conoce a maravilla Moscú, Atenas -su ciudad nativa--, Jerusalén, Constantinopla, y luego, Japón y China, y ha bebido la civilización occidental en París y en Madrid, porque es hispanista eximio. Y de aquella experiencia, y de su convivencia con los angustiados protagonistas de la revolución rusa y de la revolución china ha extraído los relatos tensos de "Toda-Raba".

Mezcla de Panait Istrati y de Malraux, con el desenfado y la fuerza pictórica de aquél, y con el dramatismo de éste, Nicolás Kazán llega a una dimensión literaria que es anuncio de futuras grandes obras. La revelación que ahora se brinda al público español, con este libro, es sencillamente imborrable. Y nadie que pasee sus ojos -y sus nervios, y su sangre- por los capitulos acerados de "Toda-Raba" olvidará que en Grecia hay un hombre que, después de eso, ha escrito el "Jardín de Rocas" y que, en la actualidad se halla empeñado en forjar una nueva "Odisea" para cantar las peripecias del alma contemporánea del nuevo Oddysseus, su compatriota y coetáneo, el hombre de hoy. "TodaRaba" tiene sello de Ercilla". 


\section{Roberto Quiroz P.: Un escritor griego fuera de Europa}

Hay que ser justo en que la nota editorial, aún en su brevedad de líneas, contiene la medida exacta como para proporcionarle a Nikos Kanzantzakis el realce propio que la posteridad le habría de dar. Quien ha escrito esa nota del año 37 quizá pudiera pecar de entusiasmo literario, de adherencia proselitista declarada pero, no obstante, en ningún caso llega a caer en palabras fáciles de exageración y adulación. Ese es el peso que tiene su obra, y hubo quien lo supo ver en aquella época. Asimismo, la propia nota se encarga de mencionar nada menos que tres importantes libros del autor, Toda-Raba, El Jardín de rocas, y un tercero que como se sabe, es la obra cumbre de su vida, la Odisea. Si no se tuviera esa nota de Ercilla posiblemente sería difícil de creer que en nuestro medio, geográficamente siempre alejado de todo, se tengan esas noticias al respecto.

Las palabras que acabamos de leer, publicadas en el remoto año de 1937, constituyen por cierto un retrato visionario de lo que hoy pensaríamos todos del escritor cretense. Al situarnos sobre aquella época y mirar desde allí los detalles que nos entrega esa nota, tenemos la inmediata impresión de su actualidad con respecto a lo que Kazantzakis mismo era en ese momento, de lo que hacía; de que era un hombre sensitivo con la mirada de un Ulises viajero, atraído por las grandes revoluciones y dándole golpes a la realidad contemporánea para llevarla a sus libros.

Finalmente, tampoco es una comparación accidental la que nos entrega la nota cuando pone a Nicolás Kazán al lado de otros nombres de reconocidos escritores como André Malraux y Panaït Istrati.

\section{Primeras traducciones en Sudamérica}

Hernán del Solar Aspillaga (1901-1985), es el nombre del visionario que consideró importante fijarse en la figura de Nikos Kazantzakis -occidentalizado en Francia como Nicolás Kazán-- para ser incluido en la tribuna de las letras universales y darlo a conocer. A este chileno le debemos pues la primera traducción de una novela de nuestro autor. Un año después, otro sudamericano, el peruano Luis Alberto Sánchez, traducía El jardín de rocas. Novela de la guerra civil china a instancias del clima de fronteras abiertas entre las editoriales y sus intelectuales.

Los datos y fechas que tenemos al respecto nos permiten configurar un cercano perfil de este intelectual local, cuya edad no sobrepasaba los 20 años de diferencia con respecto a la edad de Kazantzakis. En el medio chileno a Hernán del Solar se le conoció como un hombre de letras, crítico literario, ensayista, poeta, novelista y creador de cuentos infantiles. Como en el caso de Kazantzakis, a los tempranos años de la juventud sentirá que la poesía nace de su mano y antes de cumplir los veinte publicará un libro de poesía que no dejó indiferente a la crítica de entonces. Su devoción por las letras y la cultura universal se hizo notar muy pronto -algo igualmente presente en el escritor griego--, al dominar diversos idiomas como el inglés, catalán, francés, italiano y portugués, lo que le permitió ser pionero en la traducción de literatura extranjera. Este es otro punto de contacto en sus actividades, pues como se sabe, Kazantzakis fue un incansable difusor de la cultura universal a 
través de traducciones y adaptaciones pedagógicas. Elocuente es el caso del escritor chileno, quien fue el primero en dar a conocer en Sudamérica a Nikos Kazantzakis, algo completamente novedoso para esos tiempos. También se dio a la labor de difundir a otros nombres internacionales, tales como Stefan Zweig, Aldous Huxley, Andre Maurois, Pierre Mac-Orlan, Zilahy Lajos, Blaise Cendrars y otros.

De su vida sabemos que a partir de los años 20 se incorporó como secretario del equipo de redacción en la revista nacional Zig-Zag, ejerciendo asimismo labores de colaborador. Años más tarde, en 1928 y junto a otros escritores del medio, se hacía cargo de la edición de la revista Letras. La publicación de esta revista marcó el inicio de Hernán del Solar como crítico literario, oficio que se proyectó a partir de 1932 en otra revista chilena, Hoy.

Fruto de su interés por la teoría y la crítica literaria nacional es su libro de 1937, Índice de la poesía chilena contemporánea, en donde ofrece un panorama general de la actividad literaria creciente. Su obra más personal la componen poemarios, narrativa y cuentos infantiles.

Este es el breve bosquejo del hombre que descubrió la obra de Kazantzakis y que la quiso dar a conocer aquí, en el Chile de Sudamérica. Un hombre de letras que descubre a otro que también lo era. Sin embargo, el acierto indiscutido que tuvo Hernán del Solar se enmarca dentro de un proceso macro-contextual e intercultural, que en nuestra historicidad se conoce como la "época de oro" de la difusión de la cultura en papel. Al respecto, señala el historiador Bernardo Subercaseaux ${ }^{2}$, que en las dos décadas posteriores a 1930, el país va a pasar por una verdadera revolución cultural, y que con toda razón se la puede denominar como la "época de oro de la industria editorial y del libro en Chile". Son palabras muy para tomar en cuenta, un proceso en el que varios factores individuales y masivos se hicieron parte a la vez. Al mérito personal de Hernán del Solar para que se fijara en Kazantzakis, y luego que lo leyera por cuenta propia, se unen otros elementos ambientales que valen la pena que los situemos en perspectiva histórica.

Al hurgar en los datos del momento, al cernir la atmósfera de la estructura cultural que toma cuerpo en las casas editoriales y en los proyectos de las ediciones chilenas, uno se encuentra con lustrosos catálogos editoriales y artículos de prensa que señalan que tras bambalinas se encuentra toda una actividad editorial medianamente establecida, industrial, con proyecciones directas en el mercado continental. El mismo autor, Subercaseaux, esclarece que en esas décadas "la producción de libros tiene en el momento que sigue a la crisis de 1929 y hasta más o menos 1950, una notoria expansión”. El juicio emitido encierra notorios matices de paradoja, pues lo que sucede es que en un mismo momento de crisis hay otros espacios que se abren y que presentan una oportunidad única, a costa también de grandes desafíos. La nueva crisis europea afectará de otra manera al resto del mundo,

${ }^{2}$ Subercaseaux, B., Historia del libro en Chile (Alma y cuerpo). Santiago: LOM Editores, 2000. 


\section{Roberto Quiroz P.: Un escritor griego fuera de Europa}

no del mismo modo en que a sus comarcas, lo cual se ha dejado de ver aquí, en Sudamérica.

Elocuentes son las palabras de un testigo crucial de ese momento, Tomás Lago, quien anota en 1934: "se ha puesto en evidencia que hay un público bastante numeroso que lee [...], los editores han comprendido que la impresión de libros no es una locura comercial [...], han surgido numerosas editoriales, sobre todo a partir de 1931, fecha en que cesaron las importaciones de libros. Todos sabemos cómo empezó esta industria chilena: pequeños capitales invertidos en imprentas y librerías empezaron a producir obras traducidas de todos los idiomas [...]. La facilidad para editar obras, tomándolas libremente de los pocos ejemplares que llegaban al país, sin autorización especial alguna de los autores, permitió producir un libro barato, variado y profuso que satisfizo con largueza al público. Las novedades más recientes de la literatura mundial se encontraban en los puestos de diarios [...]. El comercio editorial se ha desarrollado profusamente al margen de la ley. Como no llegan libros de afuera o llegan sumamente recargados de precio por las dificultades de importación, cualquier obra que se publique es recibida con avidez por el público y se agota rápidamente. Se publica todo y se vende todo... Al abaratarse, la literatura ha salido de la librería para llegar hasta la calle a competir con el periódico",3.

Como vuelve a señalar Subercaseaux, "en esta expansión incidieron tanto factores económicos, como políticos y sociales. Entre los primeros está el propio crack capitalista de 1929, que hizo dificil obtener las divisas necesarias para importar libros" ". Todo este panorama de guerra y postguerra condujo las cosas por cauces diferentes, impensados. Asimismo, agrega este autor que "también tuvo incidencia la situación europea, que en medio de fascismos, turbulencias políticas y de la segunda guerra mundial, se tradujo en un campo de negocios editoriales ostensiblemente alterado en términos de comunicación, contratos, envío de libros y derechos de autor".

Hubo casas editoras a las que este contexto mundial favoreció notoriamente hasta por décadas, llevando así una línea productiva en donde la editorial se liberada de los pagos propios sobre derechos y servicios asociados. Es el caso de la casa Editorial Splendor, que a comienzos de la década del cuarenta señala, "la guerra civil española, primero, y la actual guerra mundial después, han cerrado, se puede decir, las fuentes de producción del libro, de donde se surtían los libreros americanos, y esto ha dado lugar a la formación de editoriales nativas, que cada día aumentan su producción y mejoran su calidad, supliendo en gran parte la escasez de libros que se sufrió durante un tiempo".

Tales condiciones propiciaron una especie de boom editorial chileno, el cual se mantuvo por dos décadas hasta la entrada de los años cincuenta, en donde el concierto editorial hispano comienza a abrirse paso por el lado de México y Argentina.

3 Lago, Tomás. "Los derechos de autor y el porvenir del libro chileno". Anales Universidad de Chile, 14. Santiago, 1934, p. 77 y ss.

${ }^{4}$ Subercaseaux, B., op. cit., p. 201. 
En los años del apogeo, en 1941 concretamente, nuestro Hernán del Solar da cuenta de ese gran fenómeno cultural que viene aconteciendo y escribe: "Ercilla, ZigZag, Nascimento y Cultura: estos cuatro nombres definen nuestra actividad productora de libros... son las que imprimen su sello en cuanto volumen de algún valor anda con un Hecho en Chile por las ciudades americanas. Para que se advierta el esfuerzo de estas casas editoras, basta coger el catálogo de cualquiera de ellas. Obras de todos los géneros, de todas las tendencias, de todos los tiempos",.

Ahora que hemos mirado un poco más hacia el interior del fenómeno editorial en aquellos tiempos, ampliado su significado y concomitancias, entendemos mejor que si acaso se desarrolló ese boom editorial, esa apertura de fronteras multiculturales, esto no se produjo de manera completamente autónoma o por generación espontánea, sino que hubieron derivaciones, reacciones en cadena y que tuvo como protagonismo marcado el colapso de una estructura políticamente situada en Europa. A pesar de eso, las manos pioneras de los traductores y promotores que se fijaron en un autor poco o nada conocido en la América Hispana, fueron las de Hernán del Solar y Luis Alberto Sánchez .

5 Del Solar, Hernán. "Escaparate editorial chileno 1941". Atenea, Tomo LXIX, 205, Concepción, 1942, p. 57.

${ }^{6}$ Luis Alberto Sánchez (1900-1994), es una de las personalidades peruanas más sobresalientes de la cultura americana. Su labor y su obra son prolíficas, oceánicas, las que van desde político, docente, ensayista, crítico literario, novelista y poeta, así como analista y activista político e historiador. Fue un hombre preocupado de la realidad universitaria del continente americano y, también, sobre la creación intelectual. Desterrado varias veces, desde inicios de la década del 30, por su militancia aprista, sacaría provecho de esa desventura y tejería una infinidad de relaciones con intelectuales de Chile, México, España, Estados Unidos, etc. En 1930 es profesor visitante de la Universidad de Chile. En medio de muchas actividades, en el año 1934 es nombrado director de La Tribuna. El mismo año, en Chile, es nombrado subdirector de la Editorial Ercilla, a cuya dirección llegará en cuatro años más, en 1938. Al año siguiente es Vicepresidente del Pen Club de Chile. Hacia 1953 es profesor investigador de otra universidad chilena, la Universidad de Santiago. Sus publicaciones son muchísimas y diversificadas, especialmente, en cuanto a literatura se refiere. Tres fueron las áreas donde más concentró su trabajo intelectual: periodismo, crítica literaria e historia. Su vitalidad e ímpetu laboral lo llevó en una carrera meteórica. Incansable escritor de artículos y traducciones, las que fueron a veces de uno a dos libros por mes. Una gran mayoría de ellos publicados por Editorial Ercilla de Chile. En ese periplo de estancia en Santiago, tradujo a Germaine Ramos, Pierre Lyautey, Romain Rolland, André Maurois, Waldo Frank, Elena Samios, Nicolás Kazantzaki, Henri de Montherlant, Francois Mauriac, André Malraux, Rainer Marie Rilke, James Joyce, Jorge Plejanov, Otto Strasser, F. Lefevre, B. Brutskus, E, Nort, H. Ardant, M. Mitchel, J. Benda, J. Maritain, K. Marx, y otros. Prologuista de varios libros, publicó artículos en revistas como La nueva democracia de New York, Hoy de Santiago de Chile, La Capital de Rosario, Los Andes de Mendoza, El Tiempo y Acción Liberal de Bogotá, La Revista Nacional de Cultura de Caracas. Escribir, escribir y escribir era toda su labor y actividad cotidiana durantes sus días en Chile. El porqué de esta febril 


\section{Roberto Quiroz P.: Un escritor griego fuera de Europa}

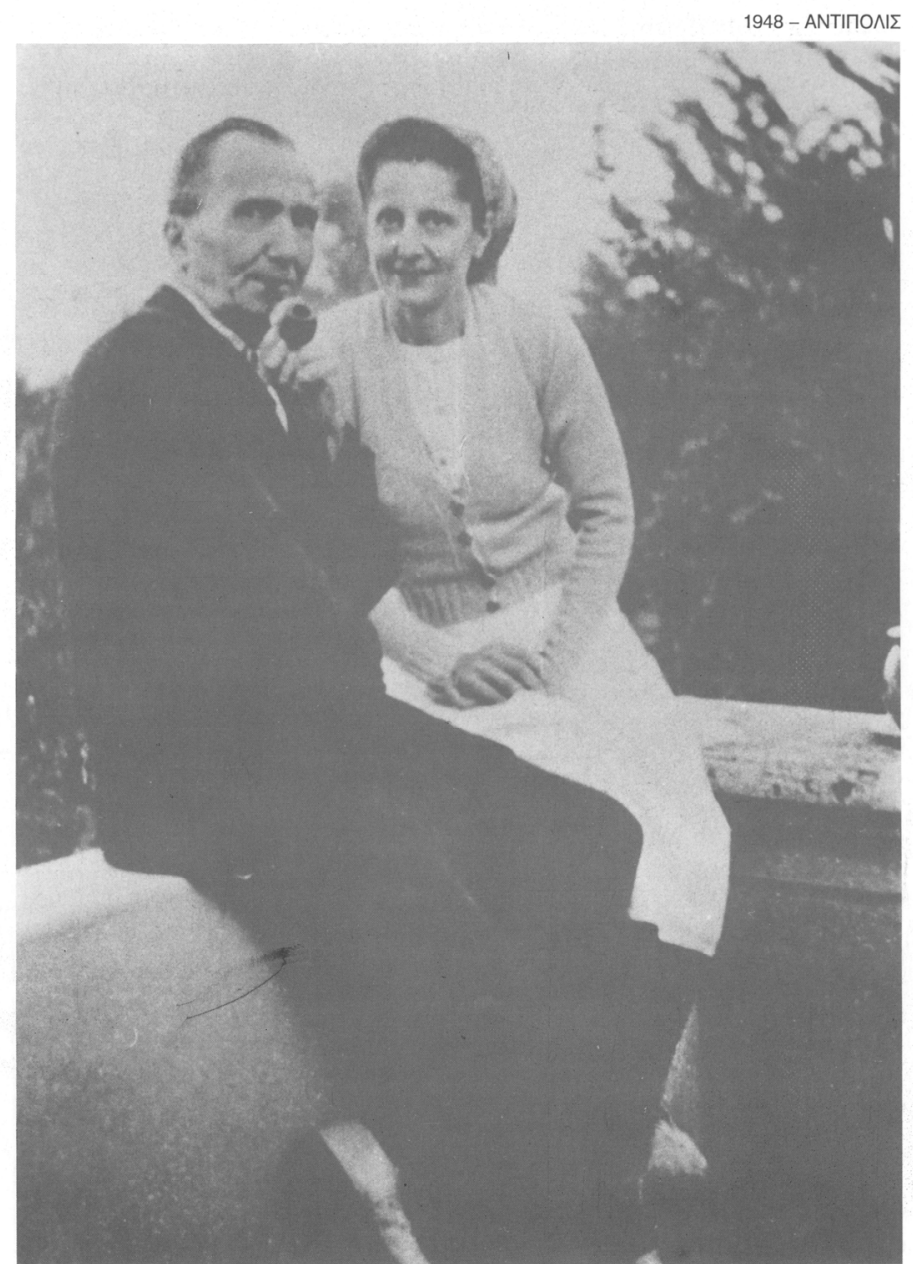

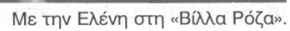

actividad es resumida en una frase del propio Sánchez: "Escribir equivalía a escapar de mí mismo" (Así aparecen los nombres referidos en las notas de L.A.S. de Nikos y Eleni (Samíu) Kazantzakis). 


\section{Un viaje que los separó}

Otra de las curiosidades editoriales y de recepción de la obra de Kazantzakis en América del Sur, se relaciona con Eleni Samíu?

¿Qué fue lo que sucedió en torno de esta mujer para que el nombre de Nikos Kazantzakis volviera a resonar en nuestra arrinconada tierra?

Esta vez la historia tiene que ver con un libro y la historia de un viaje.

En octubre de 1927, Kazantzakis viaja por segunda vez a la Unión Soviética, esta vez invitado por el gobierno. Allí desarrolla diversas actividades conmemorativas del aniversario de la Revolución. Asiste a un Congreso en el mes de noviembre. En esa reunión conoce a Panait Istrati ${ }^{8}$, quien como sabemos era greco-rumano, hijo de griega y de rumano. Por aquellos años, sus libros se editaban y reeditaban en diversas lenguas. El estímulo y la ayuda de Romain Rolland habían sido decisivos para hacer conocido este escritor, que contaba por entonces con el apoyo de los movimientos de izquierda en Europa y América. Entre Kazantzkis e Istrati surgió una estrecha amistad. De regreso, en Atenas, ambos dieron conferencias sobre lo que habían visto en Rusia. A fines de mayo de 1928, Kazantzakis viaja por tercera vez a la Unión Soviética y se reúne allá con Istrati en junio ${ }^{9}$. En Leningrado, ambos conocen a Víctor Serge. Meses después, el régimen estalinista acusa a Serge y a su suegro Rusakov y los condena. Serge morirá más tarde en el destierro. Conmovido y escandalizado, el escritor rumano protestó apasionadamente. El resultado fue el rompimiento, la "excomunión" de Istrati por el estalinismo. Los amigos se separaron bajo una probable disidencia e incomprensión. Istrati se marchó, mientras Kazantzakis permaneció en Rusia hasta abril de 1929.

${ }^{7}$ Eleni Samíu (Helena o Helene Kazantzaki) (1903-2004). Fue la segunda esposa de Nikos Kazantzakis, a quien conoció en 1924. Llama la atención que dos de los tres libros que se le conocen se publicaron en Santiago de Chile: La santa vida de Mahatma Gandhi (Ercilla, 1936), La verdadera tragedia de Panaït Istrati (Ercilla, 1930, trad. de Luis Alberto Sánchez). Su tercera publicación es muy posterior, y ya como viuda. Kazantzaki, el disidente. Nikos Kazantzakis visto a través de sus cartas, notas y textos inéditos (Planeta, 1974). Compuso un Epílogo y Anexo del libro Viajando Japón-China de Kazantzakis, con apuntes que son del segundo viaje, realizado en 1957. También agregó una Presentación al libro Carta al Greco, del mismo autor griego.

${ }^{8}$ Panait Istrati (Brãila, 1884 - Bucarest, 1935). Escritor y revolucionario rumano. En su vida estuvo la necesidad de hacer algo por los desamparados y la clase proletaria. Su activismo político encontró tribuna en la prensa socialista obrera. A partir de 1916, decide recorrer parte de Europa, Oriente Próximo y Argel. Al regreso de su último viaje a la Unión Soviética se siente muy abatido por el régimen estalinista que acababa de ver y de sufrir --actos que considera atropellos humanos. Así escribe una demoledora crítica de estos excesos estalinistas.

${ }^{9}$ Ese mismo año saldrá publicado en la revista Monde, un artículo de Istrati en el que difunde la obra de su amigo, "Parmi des gueux de Grèce: Nikos Kazantzakis". 


\section{Roberto Quiroz P.: Un escritor griego fuera de Europa}

En ese último viaje por la Unión Soviética, Panait Istrati estuvo acompañado por Bilili Baud-Bovy y Kazantzakis por Helení Samíu, quien más tarde será legalmente su esposa. Durante el viaje, Heleni hizo anotaciones y, conmovida por las experiencias vividas, escribió una especie de crónica que tituló La verdadera tragedia de Panait Istrati. La obra, escrita en francés, no se publicó hasta más de medio siglo después. Pero sí se publicó en castellano, en Chile, por Editorial Ercilla, en 1938, en traducción de Luis A. Sánchez. Tanto para los estudiosos de Panait Istrati como los de Kazantzakis, este libro presenta un gran interés. Habla de las inquietudes e ideales de ambos escritores, de sus reacciones frente a lo que van conociendo en la Unión Soviética, del doloroso episodio que marcó ese viaje, y del triste destino posterior de Istrati. Para Heleni, la tragedia de Panait Istrati tiene claramente su origen en su actitud ante el "caso Serge". Para ella, Istrati habló contra "su casa", la Unión Soviética. Y según el dicho ruso, "si hablas mal de tu casa, ella se te caerá encima".

El libro de Heleni está más escrito podríamos decir, bajo el ojo del realismo que no así por la ficcionalidad transformativa de los hechos que se alejan de quien los narra. El libro tiene el valor de ser uno de los primeros relatos testimoniales escrito, aparentemente, en el año 1928, y por una de las personas más cercanas a Kazantzakis en vida. Asimismo es una de las fuentes que ilustran, dentro de lo posible, una panorámica en el seguimiento de los pasos intelectuales del hombre cretense al lado de uno de sus amigos íntimos, y literato como él, y en este caso, con el que compartió simpatías e ideologías políticas de aquella agitada época de experiencias históricas.

En un breve escrito del año 1928, titulado "Panaït Istrati encuentra a Gorki", es en el que encontramos las impresiones de cuando Kazantzakis retrata a un hombre vibrante como Istrati que al conocer a Gorki, se desanima. Sin embargo, las palabras con que Kazantzakis pasa revista a la vida de su amigo y camarada de ideales son muy conmovedoras, cercanas, y son las que recordamos aquí:

"Encontré a Panaït Istrati en Moscú. Una atmósfera de campo militar reinaba ese día en la ciudad engalanada. Al igual que yo, había sido invitado por la Unión Soviética a las grandes manifestaciones del décimo aniversario de la Revolución.

[...]Tan pronto como cumplió los doce años, el muchacho abandonó a su madre y comenzó su vida errante. Pasó hambre, cayó enfermo y durmió en las calles. Escondido algunas veces en las bodegas de buques, otras en los vagones o detrás de los camiones, recorrió clandestinamente Egipto, Palestina, Siria, Grecia, Suiza e Italia. Le quemaba una insaciable sed de vivir, de ver y de gustar todas las alegrías y todas las penas que el hombre puede experimentar en esta tierra.

En el curso de sus vagabundeos lee literatura rusa, escucha historias orientales y los cuentos de las Mil y una noches $[\ldots]$. 
Byzantion Nea Hellás 28, 2009: 207-234

Un día de Enero de 1921, cansado de pasar hambre y de sufrir, decide matarse. Dos años antes, habia escrito una carta de veinte páginas a Romain Rolland, en la que explicaba su vida dura y su necesidad de escuchar una voz amiga y de estrechar la mano de un verdadero hombre.

Encontrar un amigo fue siempre el ardiente deseo de Istrati. Más que el amor, más que las riquezas y la gloria, es la amistad la que ha ocupado en su vida y en su obra el sitio primordial: entregarse a un amigo, que este amigo se entregara a él y juntos, inseparables, emprender la gran aventura de la vida. Con frecuencia habia caido en esta dulce trampa, pero los amigos le habian traicionado e Istrati se había encontrado solo en el desierto humano". ${ }^{10}$

${ }^{10}$ Kazantzakis, N., Del Monte Sinaí a la Isla de Venus. Traducción del francés Andrés Lupo Canaleta, Editorial Planeta, Barcelona, 1962, vol. II, p.1053 y ss. 
Roberto Quiroz P.: Un escritor griego fuera de Europa

1927 - PQSIA

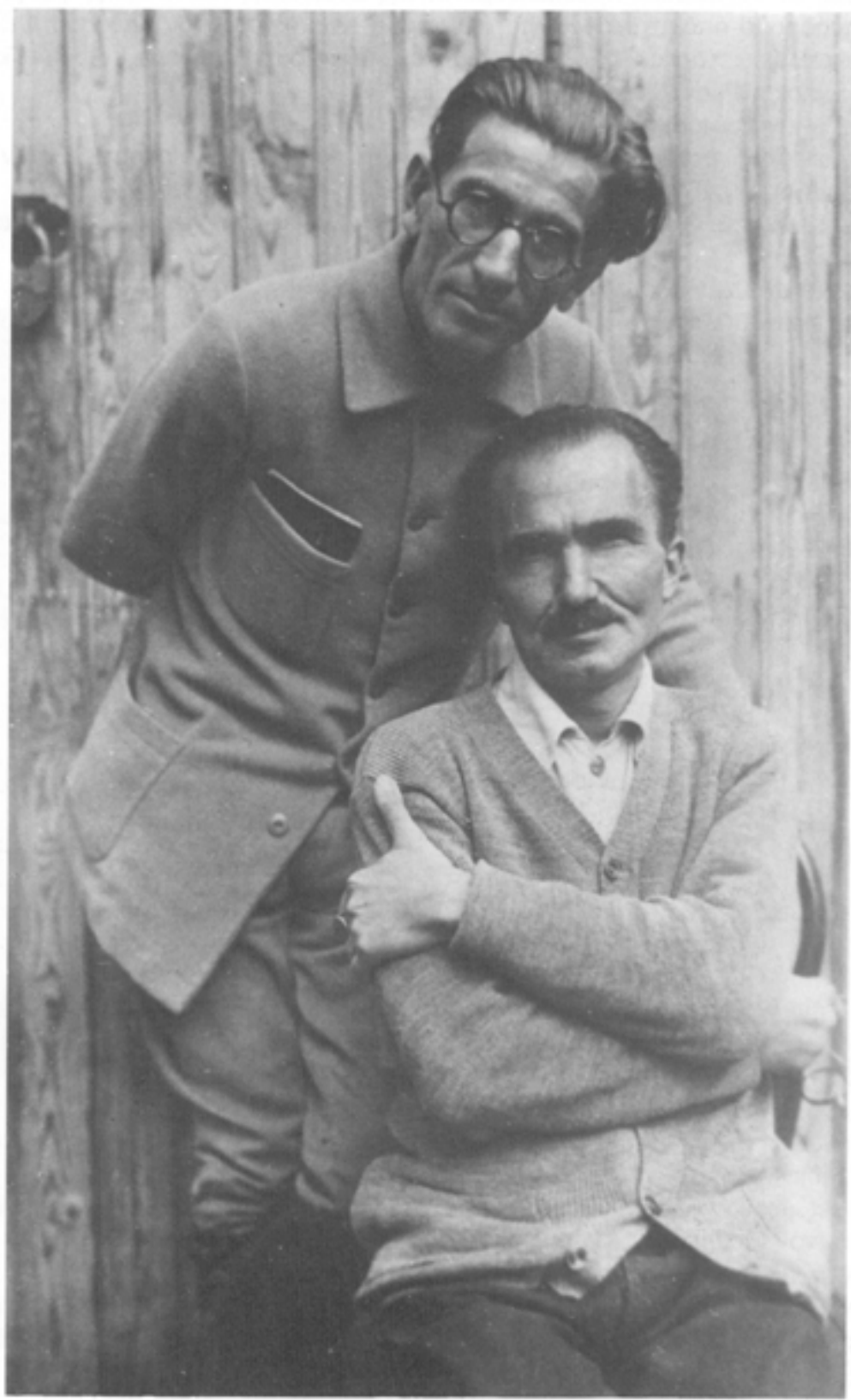

Me tov П. Iotpát. 


\section{Novela}

La decantación noveslística fue lo que trajo la consagración definitiva de Kazantzakis. Su creación dramática llegó más tarde a esta parte del mundo.

En contraste con lo que sucede con el teatro, sólo tres novelas se tradujeron en Chile y sólo dos aparecieron en el país. Como se ha expresado con anterioridad, Toda-Raba, que la escribió Kazantzakis en 1929, será publicada en 1937; y El jardín de rocas, obra originaria del año 1936, va a ser editada en 1938. Ambas obras fueron vertidas del original francés al castellano por Hernán del Solar y Luis Alberto Sánchez respectivamente, y editadas por la editorial chilena Ercilla.

La primera novela de juventud de Kazantzakis, escrita en forma de epistolario y fechada en el año 1906, fue traducida por Miguel Castillo Didier, a pedido de la segunda esposa, la señora Heleni Kazantzaki. La traducción de Lirio y serpiente, título de la obra, se realizó en Venezuela y Carlos Lohlé la editó en Buenos Aires, en 1988.

Asimismo como antes en Europa, la expansión masiva en el caso de Hispanoamérica sobrevino con las novelas Vida y hechos de Alexis Zorbás, que apareció bajo el título de Alexis El Griego en las Ediciones Peuser, del año 1954, y traducido del francés por Roberto Guibourg.

La otra novela célebre fue Cristo de nuevo crucificado -con traducción desde el francés de José Luis de Izquierdo, en 1954--, cuya divulgación se debió al editor holandés Carlos Lohlé, admirador y amigo de Kazantzakis. Así recuerda Lohlé la edición de esta novela: "Cuando poco tiempo después apareció la novela en castellano en Buenos Aires, tuvo una enorme aceptación. En pocos meses hicimos edición tras edición. Kazantzakis quedó encantado con el éxito de su libro en idioma castellano" ${ }^{\prime 1}$.

Hay una sexta novela editada en Sudamérica, Libertad o Muerte, cuya primera edición corresponde a la de Carlos Lohlé, en el año 1957, y cuya traducción corrió por cuenta de la escritora española Rosa Chacel.

\section{Teatro}

La consagración de sus novelas le abrió enseguida las puertas a la difusión del teatro. Otra vez comenzó a ser traducido desde estas latitudes, teniendo como focos principales Argentina y Chile.

Melisa fue la primera obra de teatro que se tradujo en Sudamérica. Estuvo a cargo de Roberto Guibourg y fue editada por Losange en Buenos Aires, en el año 1957.

Al año siguiente, en 1958, Luisa Rivaud y Raquel Wars-Chaver, editan en la misma casa editorial Losange, Teseo, siendo la segunda traducción vertida desde el francés.

\footnotetext{
${ }^{11}$ Lohlé, C., Presencia y experiencias, ed. Carlos Lohlé, Buenos Aires, 1986, p. 250.
} 


\section{Roberto Quiroz P.: Un escritor griego fuera de Europa}

Chile no se queda atrás en este ámbito teatral y a las traducciones argentinas mencionadas, se suman ahora las traducciones directas del griego de las obras Cristóbal Colón y Constantino Paleólogo.

Cristóbal Colón es la primera pieza del género dramático que se traduce directamente y por un autor chileno, Miguel Castillo Didier. Sin embargo, se publicó en Argentina por Ed. Carlos Lohlé, en 1966. A la fecha Cristóbal Colón suma 10 ediciones, la primera en Argentina, dos en Venezuela (1982 y 1988) y 7 ediciones en España. La última de ellas, la décima, fue una coedición entre la Universidad de Granada y la Universidad de Chile del año 1997.

Representaciones teatrales de esta misma obra tan cercana al sentimiento de España y América toda han sido varias. Se presentó en Argentina, Ecuador, Venezuela, México y España. La última de sus presentaciones se hizo en la ciudad española de Santa Fe, en 1997. Es la obra teatral con más ediciones y más presentaciones en el mundo.

En la lista de traducciones le sigue Constantino Paleólogo, editada por Ediciones Santiago en 1967. Es la primera obra publicada en Chile y la segunda en versión directa. Su traducción es la de M. Castillo Didier.

Las traducciones y ediciones en el ámbito nacional continúan con un libro que recoge cuatro tragedias; es el vol. 1 de Teatro: Odiseo, Juliano el Apóstata, Nicéforo Focás y Kapodistria. Contiene un Prólogo de Fotios Malleros, fundador y director del Centro de Estudios Griegos Bizantinos y Neohelénicos de la Universidad de Chile. Es la primera publicación universitaria que se conoce y que constituye una categórica divulgación del autor. Se publicó el año 1978. Todas las tragedias en traducción directa de M. Castillo Didier.

Se suman la trilogía de Prometeo -el primero, Portador del Fuego apareció en el 1998, y el segundo, Encadenado del año 2000. Estos dos han sido publicados en forma de folleto. Permanece inédito el tercero de ellos, Prometeo liberado. Todos editados por el Centro de Estudios Griegos Bizantinos y Neohelénicos. Traducción a cargo de M. Castillo Didier.

Una de las obras de teatro que más esfuerzo y dedicación demandó a Kazantzakis fue Buda. Pasó años bajo revisión y nuevas versiones. "Su tragedia más extensa y en la que trabajó duramente más de dos décadas es Buda, comenzada en 1922. La reescribió en 1941, durante el retiro forzado en Egina, bajo la ocupación alemana. Y la reelaboró totalmente en 1950, en su autoexilio de Antibes ${ }^{, 12}$. La pieza fue traducida por Miguel Castillo Didier, y tuvo su primera edición en Carlos Lohlé, en 1981. La edición contó con una interesante introducción de Peter Bien.

La última obra escénica traducida y representada en latitudes chilenas es Comedia-tragedia en un acto, vertida del griego por Roberto Quiroz Pizarro. La publicó el Centro de Estudios Griegos Bizantinos y Neohelénicos de la Universidad

${ }^{12}$ Quiroz P., W. R., Nikos Kazantzakis Impromptu filosófico: dimensiones de un poeta pensador. Centro de Estudios Griegos Bizantinos y Neohelénicos de la Universidad de Chile. Santiago, 2003, p. 118. 
de Chile. Hasta la fecha cuenta con dos ediciones, la primera del año 1998 y la segunda de 1999. Otra curiosidad de esta pieza es que apenas fue traducida de inmediato se presentó en el teatro de la Facultad de Artes de la Casa de Bello, en 1998, y es la única representación en el mundo. El director del montaje fue el profesor Héctor García Cataldo.

Comedia es la pieza dramática de Kazantzakis más antigua que tenemos traducida al español. La obra apareció publicada ya en el año 1909, en la revista de Creta llamada Kritiki Stoá.

\section{Otras obras $^{13}$}

Para la traducción en Sudamérica de la Ascética hay más complejidad en juego. Hubo una fijación del texto realizada por Aziz Izzet que toma en cuenta otras versiones. Izzet la establece en francés añadiendo una interesante Introducción. A partir de esta versión francesa es de donde Delfín Garasa hizo su traducción española que fue publicada por Carlos Lohlé, teniendo su primera edición en marzo de 1975. El mismo traductor, D. Garasa, se sirvió de la versión inglesa del Simposio para su traducción. La edición es de Carlos Lohlé, en mayo de 1978. La edición asimismo contiene una recomendada Introducción de Teodora Vasils.

Otro libro a mencionar es Apuntes de viajes. Textos inéditos en español de Nikos Kazantzakis, un trabajo de Roberto Quiroz Pizarro. Se publicó en el Centro de Estudios Griegos Bizantinos y Neohelénicos. Cuenta con dos ediciones: la primera de 1997, y la segunda en el año 2000.

No se trata de un libro propiamente tal que escribiera Kazantzakis con ese título y contenido, sino que corresponde a la elaboración de una antología a partir de textos que fueron escritos por él en sus viajes. Sabemos que Kazantzakis les dio vida a sus experiencias y recuerdos de viaje en diversos textos que los denominó en griego taxidévontas, lo que literalmente significa viajando. Otra adaptación sería Cuadernos de viaje. Su autor los agrupó con el tituló Viajando Inglaterra, Viajando China, etc. Aquí, en esta selección, se presentan capítulos tomados de los libros Viajando Inglaterra, Viajando Rusia y Viajando Italia-Egipto-Sinaí-Jerusalén-Chipre-Morea.

13 Aludimos a escritos singulares de Kazantzakis, uno de ellos, Ascética que no se enmarca dentro del canon novelesco o dramático que venimos siguiendo hasta ahora. Simposio, que guarda una evocación modélica con el texto platónico, constituye junto a la anterior otro de los núcleos ideológicos en sí, intensamente filosóficos. Apuntes de Viajes que viene a ser como islas vírgenes en el pensamiento de Kazantzakis, en donde reflexiona sobre personajes y lugares del espíritu. 


\section{Roberto Quiroz P.: Un escritor griego fuera de Europa \\ Odisea}

Finalmente, llegamos a la monumental Odisea que es un caso aislado dentro de la producción de Kazantzakis y que merece más atención.

Se trata de un monumental poema epopeya de 33.333 versos, cuyas dificultades son las mayores que se le pueden presentar a todo traductor.

Las primeras traducciones de la Odisea a lenguas foráneas son: la primera versión inglesa de Kimon Friar, en 1958; la traducción sueca comenzada por Börje Knöss; la traducción en Francia de Jacqueline Moatti, aparecida en 1968: y la versión española de M. Castillo Didier, publicada en 1975.

Las dificultades traductológicas de la Odisea no sólo se deben a las inherencias idiomáticas de una lengua riquísima o a la sin igual pléyade de lirismos que recorren como oleajes salvajes sus versos y rapsodias, sino que constituye un desafío mayor y aparte por tratarse nada menos que de la obra suprema de Nikos Kazantzakis, una de las obras cruciales de la literatura neohelénica y contemporánea. Para ilustrar lo que decimos basten unas palabras de su propio autor en una carta al helenista sueco Börje Knöss, en 1954: "Creo que toda mi alma, toda la llama y la luz que he podido hacer brotar de la materia de la que estoy moldeado, se expresan en la Odisea; mis restantes obras son secundarias $" 14$.

El hilo argumental de la obra tampoco es simple de retratar. El propio traductor al castellano entrega en paralelo a la Odisea, una especie de síntesis que ayuda al lector. El itinerario del protagonista homérico que va llegando a su final, entrada la rapsodia XXII, va a servir de punto inicial para el héroe de Kazantzakis. Una Odisea nace donde la otra parece acabar. Desde finales del poema homérico, en que Odiseo recién ha terminado de dar muerte a los pretendientes de Penélope, aparece ante nosotros el nuevo héroe kazantzakiano. "Desde su primer encuentro con su esposa, su hijo y su padre, una sensación de desencanto empieza a hacerse fuerte en él. El hogar y la isla tan anhelados se le hacen estrechos y enseguida asfixiantes. Tras vivir varias experiencias negativas, luego de haber enterrado a Laertes y haber casado a Telémaco con Nausícaa, Odiseo parte de nuevo, con unos pocos compañeros -rudos aventureros. Una madrugada deja Itaca sin tumbo predeterminado"15. A partir de aquí el héroe trágico, Odiseo, se sentirá libre para nuevas búsquedas y desmantelar con sus actos los vicios y las viejas tablas de la humanidad. Sin embargo, tal anhelo de adecuación ideal entre el ser humano y las tendencias que mueven a este protagonista comienza a dejar en evidencia nuevas crisis, nuevos desafíos.

El título de la obra, las XXIV rapsodias del relato, la estructura de poema y epopeya en ambos casos, algunos personajes que reaparecen en la Odisea moderna, los temas de fondo en cuanto a viajes y experiencias, aventuras y búsquedas humanas,

14 Kazantzakis, N., Eleni, Kazantzak, el disidente. Nikos Kazantzakis visto a través de sus cartas, notas y textos inéditos. Planeta, Barcelona, 1974, p. 425. Es lo que le expresa en una carta a B. Knös, en 1954

${ }^{15}$ Quiroz P., R., op. cit., p. 320. 
en fin, al ser todos ellos tomados en cuenta bajo una visión de conjunto permitirían al menos, hacer presumible que el poeta cretense contemporáneo se inspiró en el poeta jonio, pero como bien lo señala García Gual, "el poema [...] es una extraña continuación épica y utópica del relato homérico, atravesado por las ideas e inquietudes de nuestro siglo" ${ }^{\text {"16 }}$. La nueva Odisea salva la distancia si bien retoma el fondo mítico del tema uliseano de Homero, y la salva porque a la vez va más allá, se interna en parajes desconocidos que son únicos, encuentra un sentido y un suelo propio como obra conceptual. No quiere decir que se aleje por completo, que sea un mundo definitivamente aparte. Kazantzakis ha tomado en préstamo parte de lo hecho por Homero, al punto que se identifica nada menos que con el mismo personaje central llamado Odiseo, y lo hace portavoz de su más extensa y trabajada obra. Sin embargo no es tan inmediato ni tan simple hablar de una inspiración, continuidad o paralelismo entre ambas obras. Hay que apreciarlas como horizontes de mundo que se abren y que en su expansión se circunvalan en movimientos propios y tangenciales. Por ejemplo, un estudioso destaca uno de los lazos que unen al nuevo Odiseo con el antiguo: "Con acento épico y majestuosa imaginación, Kazantzakis ha intentado completar la Odisea de Homero. El Odiseo de Kazantzakis es demasiado complejo mentalmente: refleja a Kazantzakis, un cretense que, como los de antaño, sufrió todas las corrientes intelectuales que cruzaron por la isla. En este Odiseo se agitan todos los problemas del hombre ante la verdad. En este sentido es homérico, y, por ello, Odiseo es siempre actual, como imagen del hombre que explora todo",17.

El tema es más complejo y largo, y así lo ha hecho ver Castillo Didier en su estudio La Odisea en la Odisea ${ }^{18}$. Las peripecias del héroe homérico nacen de una fatalidad, de un destino que se impone a menudo sobre los deseos humanos. Ulises busca su patria, su Itaca, su familia, porque es allí donde están por ahora el sentido de su vida, y la historia que sabemos es la necesidad de regresar, de volver a ser el mismo de antes de partir de Itaca. En la Odisea moderna, el héroe se encuentra en una misma apertura de búsquedas y sentido - lo que antes fuera tierra, familia, o la isla conocida--, de tal modo que lo que ayer y lo que ahora sucede pueden configurar ese núcleo antropológico de toda odisea, la manera de estar en camino con uno mismo y encontrar una respuesta vital al problema de la existencia. Lo que en la Odisea homérica comenzó a ser una manifestación más visible del personaje eje sobre la decantación de su personalidad, en donde su persona, "cada vez más alejada de los héroes de Troya, se hizo más humana" 19 , va ahora cobrando más vigor en la Odisea de Kazantzakis. La humanidad del héroe es un aspecto que une y conecta a las dos obras indiscutidamente.

${ }^{16}$ García Gual, C., "Introducción” a Homero, Odisea. Traducción de José M. Pabón, Gredos, Mdrid, 200, p. xxi.

${ }^{17}$ Ramos, O., La Odisea: un itinerario humano, Instituto Caro y Cuervo, Bogotá, 1970 , p. 176.

${ }^{18}$ Castillo, M., La Odisea en la Odisea. Estudios y ensayos sobre la Odisea de Kazantzakis, Centro de Estudios Griegos Bizantinos y Neohelénicos, Santiago, 2006-2007.

${ }^{19}$ Reboreda, S., "Odiseo, el héroe peculiar", en J. Bermejo-Reboreda, S., Los orígenes de la mitología griega, Akal, Madrid, 1996, p. 332. 


\section{Roberto Quiroz P.: Un escritor griego fuera de Europa}

La Odisea moderna ha dado mucho de que hablar, más cuando el tema homérico no puede dejarse de lado pero tampoco es algo que la agota, pues las pretensiones filosóficas de Kazantzakis le han valido el hecho nada menor de que su obra sea calificada como la pieza más controversial y monumental de toda la literatura neohelénica. Agreguemos que, por cierto, no fueron menores las controversias y las incomprensiones literarias que se sustentaron en torno a la cuestión de la naturaleza misma de una obra tan vasta como la Odisea. El propio Kazantzakis entró en polémicas con críticos de la época y escribió algún artículo en la revista de letras $N e a$ Hestía.

Estas palabras constituyen una mínima base para apreciar las posibles conexiones de continuidad y diferencia, paralelismo y complementación, identificación y ruptura, etc., que están detrás de estas dos grandes obras. Sin embargo, y pese a la magnitud del tema aludido se hacía necesario, al menos, aquí, esbozar algo, dejar unos puntos referenciales al futuro lector de estas obras.

Los traductores, todos por igual, sin excepción, sabían de la magnitud de la obra a la que se enfrentaban e hicieron por ello un esfuerzo loable que nos permite acercarnos a Kazantzakis de manera privilegiada, pues aunque no se crea -no lo hemos querido poner al descubierto para no confundir aquí, involuntariamente, al lector--, el problema lingüístico que se ha arrastrado en la historia del pueblo griego, sigue siendo causa de dificultades etnolingüísticas e idiomáticas aún para los propios heleno hablantes. Los que conocen las traducciones -inglesa, francesa, española, etc.-, no se encuentran con esa complejidad de fondo. Entonces, no es de extrañar que la labor de traducir la Odisea sea muy ardua y difícil. No se trata sólo de la extensión: 33.333 versos decaheptasílabos. Está la gran riqueza de la lengua y la riq74ueza del contenido, los hechos, los personajes, los episodios, los paisajes; la casi increíble sucesión de imágenes; el verdadero diluvio de compuestos que no pueden corresponder a una palabra en español. A todo ello hay que agregar la riqueza del léxico, las muchas palabras desconocidas en la lengua común; las formas dialectales especialmente cretense; los vocablos creados por el poeta. Kazantzakis tenía conciencia de que su texto no sería fácil para sus propios compatriotas y por eso adjuntó a la primera edición un folleto con un nutrido glosario. Demás está decir que a los katharevusianos no podían sino parecerle abominable la lengua de la Odisea. Pero como los prejuicios que engendraba la diglosía también afectaban a los demoticistas, hubo de parte de no pocos de éstos una reacción contraria al lenguaje utilizado en el poema. 
Byzantion Nea Hellás 28, 2009: 207-234

1954 Kalokaipt - ANTInONI

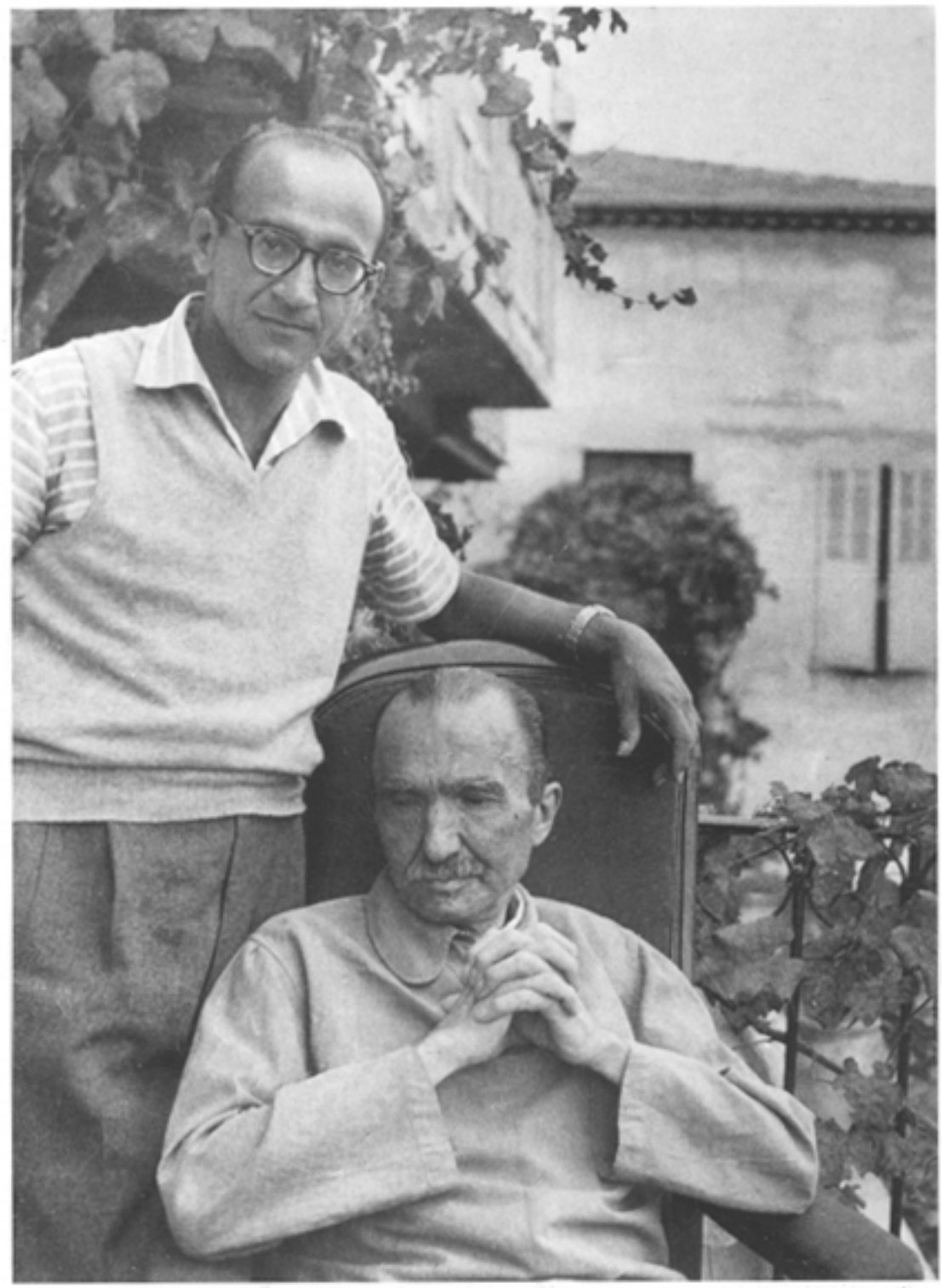

Me row Kifuovva Фpádiop. 


\section{Roberto Quiroz P.: Un escritor griego fuera de Europa}

\section{Traducción inglesa}

Hacemos notar que resulta curiosa la situación dada con esta obra, la Odisea, en cuya trama y aventura literaria parecen embarcarse los traductores y ser llevados a la fuerza a participar en alguno de sus escenarios o motivos narrativos. Quizá "la melancolía" andina, el "único elemento autóctono de nuestras letras", como se ha dicho, contenga una atracción propia, un llamado irrenunciable para quienes escriben o sienten en la sangre una especie de literatura más viva.

Kimon Friar tomó a su cargo la traducción inglesa de la obra. El trabajo se inició con una beca Fulbrigth que le permitió viajar por disímiles rincones del mundo. Con sorpresa para nosotros, descubrimos que la obra se fue terminando -finalizando en detalles, puliendo su corrección, o viendo consultas de última hora, etc.--, en tierras de Chile, específicamente en la ciudad de Antofagasta, en pleno desierto de Atacama $^{20}$. Quizá sin haberlo previsto nunca antes, el propio Friar, éste hombre de hondas raíces griegas, viajó al sur del mundo acercándose al lugar de muerte del incansable héroe Odiseo.

En la traducción inglesa, Friar contó con la buena voluntad de sentirse apoyado directamente por Kazantzakis, dado que pudieron estar en contacto personal como colaboradores de ese proyecto primero, y luego como amigos. Tenemos el testimonio de esta experiencia que aparece dentro de los Agradecimientos que Friar dedica en su traducción:

"Fue Nicolás Hadji-Kyriaco Ghika quien me habló primero con entusiasmo de la Odisea y me mostró las 20 o más ilustraciones que él ya había completado para el poema, esperando estar a seguro de la reproducción antes de asumir su proyecto completo. Me da gran placer saber que mi traducción al inglés lo ha estimulado a completar su plan y ha hecho posible la primera impresión de sus magnificos dibujos[...].

Lo conoci personalmente a Nikos Kazantzakis y su esposa, Helena, en una hostal de estudiantes en el verano de 1951. Después de una media hora de copiosa charla, él exclamó que seguramente yo debía haber leído toda su obra porque, con la excepción de su amigo de la infancia, el señor Pandelis Prevelakis, él sentía que no había conocido a alguien que pareciera entender tan bien su pensamiento. Si embargo, en ese tiempo yo sólo habia leído esas secciones de la Odisea, que había traducido para las ilustraciones de Ghika, pero nuestra futura colaboración nos confirmó a ambos en lo que sentíamos el uno por el otro en

${ }^{20}$ Kety Farandato Politis, prima del traductor avecindada en la ciudad de Antofagasta, fue testigo presencial y entusiasta colaboradora de las labores que se prolongaron por espacio de unos nueve largos meses en dicha ciudad nortina. 
Byzantion Nea Hellás 28, 2009: 207-234

personalidad y pensamiento. Yo estuve 4 meses con Kazantzakis y su esposa en el verano y otoño de 1954 en su casa de Antibes, sobre la rivera francesa, leyendo con él cuidadosamente su poema palabra por palabra [...].

Mi traducción ha implicado mi propio circuito de Odisea, pues yo trabajé en el poema en Duluth, Chicago y New York, en muchos barcos y aeroplanos, sobre varios mares y océanos; en Antibes, Cannes y Niza; en Atenas y Esparta; en varias partes de la Arcadia en el Peloponeso; en Tesalia, Tracia y Macedonia; en las blancas habitaciones de muchos hoteles a orillas del mar, en las islas mediterráneas de Egina, Poros, Hydra, Andros, Itaca, Kerkyra, Creta, Kios, Lesbos, Limnos, Samotracia y Thasos; en los alpes yugoslavos y ahora finalmente aquí, al otro lado del mundo, en Antofagasta, Chile; y yo estuve haciendo revisiones $y$ corrigiendo pruebas en Santiago, Puerto Montt, Aisén, Coyhaique, Buenos Aires, Montevideo, Sao Paulo y Río de Janeiro "21.

Como lo señala el mismo Kimon Friar, su trabajo estuvo concluyéndose en tierras de Antofagasta, en donde además escribió la Introducción y el Apéndice. Vemos que aprovechó la ocasión para abandonarse como un Ulises moderno y recorrer otras tres ciudades del austral territorio de Chile.

\section{Traducción española ${ }^{22}$}

La traducción chilena tuvo una duración de cuatro años de trabajo, desde 1966 hasta el año del comienzo del gobierno del presidente Salvador Allende, por el año 1970. No hubo contacto con Kazantzakis ni con su tierra, sólo contacto epistolar con la viuda de Kazantzakis, Heleni. La obra fue publicada en España por la Editorial Planeta en el año 1975.

${ }^{21}$ Kazantzakis, N., The Odyssey. A modern sequel. Traducción, Introducción, Notas, Sinopsis de Kimon Friar, Ed. Simon and Schuster, New York, 2a, ed. 1958.

${ }^{22}$ En la actualidad, una de las curiosidades de las que podríamos calificar de odiseicas para aplicarlo exclusivamente a la propia Odisea, sería una que tiene que ver con la traducción española de la que estamos tratando. Lo que sucede es que está pendiente la posible publicación en edición bilingüe de esta obra cumbre, en la traducción de M. Castillo Didier, revisada por él durante el año 2006, en un programa de la Universidad de Ioanina de Grecia, y coordinado por el profesor E. Kapsomenos. Al parecer, el litigio judicial suscitado en torno a los derechos de autor está causando la postergación de tal edición. Más allá de esta odisea en la Odisea, lo cierto es que se trataría de la primera edición en dos lenguas, la original y la española, de una obra de Kazantzakis. 


\section{Roberto Quiroz P.: Un escritor griego fuera de Europa}

A diferencia de lo sucedido con Friar, a quien la traducción lo condujo hacia el finis térrea, como ya vimos, la traducción en castellano acontece y finaliza evidentemente en esta zona del mundo, donde la aventura ficticia del héroe griego alcanza su desenlace en los hielos del sur. Sin embargo, la traducción de la Odisea no será un viaje biográfico hasta que en contra de su voluntad, el traductor tendrá que viajar al exilio en 1976. Hasta ese entonces el traductor chileno nunca había salido de su país. Por esos años, más que oscuros y que van del 73 en adelante, la geografía humana de Chile sufrirá el rigor de la dictadura militar. Mientras tanto, la Odisea se estaba corrigiendo poco a poco, labor que se había comenzado en el año 1970. El Prólogo de la obra quedó preparado antes del golpe de Estado, el que por consecuencias directas enmudeció a los intelectuales. Bajo este clima de ocupación queda cautiva la Odisea del escritor griego.

La monumentalidad de esta obra de Kazantzakis demandó de su traductor tres largas correcciones antes de dejarla libre. En las escasas confesiones en que el traductor comenta sobre su trabajo de esos tiempos, nos admite que le asediaban problemas de conciencia al dedicar sus esfuerzos a una obra de tal relieve poético y humano, al hacerlo en las mismas horas en que una nación sufría desmanes contra la humanidad. Huellas de este soterrado sentimiento de culpabilidad harán que el traductor ponga unas líneas denominadas Post Scriptum, fechado en enero de 1974. Fueron palabras que no se detuvieron ante el opresor.

Post Scriptum expresa la odisea personal que bien podrían compartir el héroe incorpóreo de Kazantzakis con el hombre de carne y huesos, primero exiliado de la libertad de su propia tierra; y más tarde arrojado a otras latitudes de Sudamérica, a Venezuela. Allá surgiría de su pluma el ensayo titulado La Odisea y el exilio: itinerarios del saber y del dolor. Las dos Odiseas, la homérica y la moderna, tendrán lugar en ese singular escrito.

Unas líneas del Post Scriptum de M. Castillo Didier enlazan estas circunstancias desgarradoras:

"Hasta cierta medida resulta natural la tendencia a contraponer tragedias reales y cercanas al drama poético creado con deslumbrante barroquismo de verbo e imagen $y$ cierto constante y árido cerebralismo. Las reflexiones tienden, por una parte, a hacerse quizás más severas, pero también, por otra, algunas perspectivas podrían ampliarse. En la realidad como en el poema, la vida segada y la esperanza ahogada conducen a la desesperanza. Así, el signo de la Odisea, la no-esperanza, cobra también vigencia dolorosa en millones de seres, en las latitudes muy lejanas [...] $]^{, 23}$.

${ }^{23}$ Castillo D., M., "Post Scriptum" a la Odisea de Nikos Kazantzakis, Editorial Planeta, Barcelona, 1975, p. 1210. 
Byzantion Nea Hellás 28, 2009: 207-234

En esta versión en concreto, podemos imaginar que no sólo el personaje ficticio Odiseo irrumpe hacia la frontera de la nada, mientras más se interna hacia el ignoto continente blanco, sino que la misma situación existencial y política en que trabajaba el traductor de la Odisea, parecía encarnar el dramatismo de aquella obra colosal, simulaba reflejar aquellas horas en que el mundo nos parece morir más deprisa y en que estamos solos, sin héroes, sin patrias, sin ideales que salvar.

Esa coincidencia, no buscada, entre el nihilismo conceptual de la Odisea y el propio escenario en ruinas humanas de un país en dictadura, le otorgan un matiz especial a la traducción castellana, algo como un dolor vivo que cantan sus versos.

Lo sucedido en Chile y con el traductor, no es un caso aislado, una ligazón al azar. La escritura de Nikos Kazantzakis ha marcado vidas y momentos humanos que pueden ser insospechados. Señalamos un testimonio que nos ofrece el incansable editor holandés, Carlos Lohlé:

"En el momento más triste y trágico de la historia argentina recibi de un desconocido, desde la cárcel, una carta suplicándome que le enviara alguna lectura".

Pasa el tiempo, y nuevamente, un día cualquiera, Lohlé encuentra otra nota de ese mismo desconocido:

"[...] no sé cómo agradecerle. He leído los libros mandados, y luego los pasé a mis compañeros. Si hemos podido aguantar esta vida atroz, es gracias a los libros de Kazantzakis,"24.

${ }^{24}$ Lohlé, C., op. cit., p. 250 y ss. 


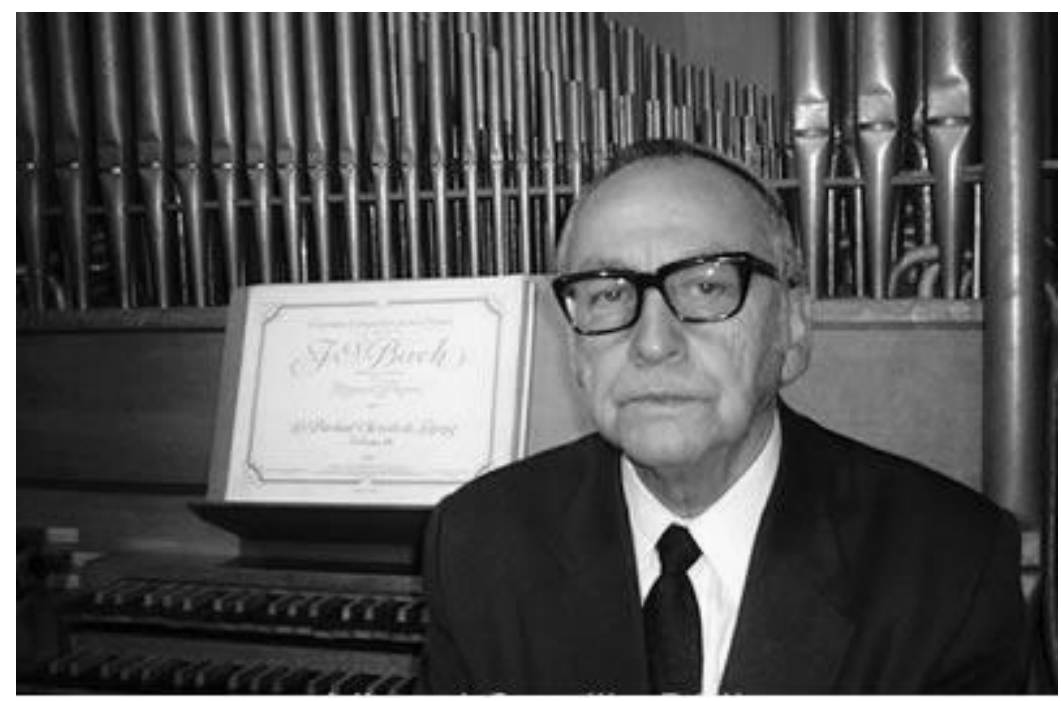

\section{A modo de conclusión}

\section{Un escritor llega a América}

Esta historia y otras historias que no conocemos aún pero en las que sí creemos, permiten desvelar una parte de ese misterio que le dio a Kazantzakis un lugar próximo en nuestros corazones en la América del Sur. Porque Kazantzakis, el cretense, el inconformista, el viajero de todos los tiempos, el navegante de las utopías perdidas, el sin patria o el apátrida de la tierra, el corsario de los siete mares, ha llegado al Nuevo Mundo para conquistar estas tierras sin otras fuerzas que las de la propia libertad de exploración, y a veces en completo silencio pero siempre tras el ascenso del hombre. Apareció aquí, no más que con unas semillas de palabras y de visiones no segadas por el tiempo; esas -sus tesoros--, a las que un día ya no muy lejano el mismo Kazantzakis les infundiera un hálito rebelde, un cercano grito espiritual, con el único propósito de hacerlas navegar en el barco de su humanidad.

Arribó un lejano día de 1937, no por ser estas unas mejores tierras que otras. Unos vigías desde la Cordillera comprendieron sus anhelos, e iniciaron el camino de la traducción. Así fue que sus primeras obras -traducidas-- llegaron como una primicia de quien con el paso del tiempo iría ganando una visibilidad mayor, un lugar, un encuentro con un mundo lejano, remoto. Sin duda que se trataba de una empresa difícil, de una odisea, porque al ser tan viajero Kazantzakis se iba haciendo una 
imagen tangible de sus posibles lectores, una fisonomía de los que podían estar en Europa, en Rusia o en el cercano o lejano Oriente.

De las Nuevas Indias no tuvo experiencia directa ni tampoco exploraciones propias de un viajero, y sin embargo, quizá el contacto fraternal con el editor Carlos Lohlé, le dio un rostro amigo en estas latitudes. Kazantzakis no se aventuró en vida por estas tierras pero su imaginación sí pudo llegar, nada la detuvo y, he ahí que vino en su nombre un loco visionario como Cristóbal Colón, o un Odiseo, el héroe griego, que llegó a consumar aquí su testamento filosófico de la Odisea.

Kazantzakis no viajó al finis terrae, lo sabemos, pero tanto alcanzó a navegar con su obra hasta nosotros, que un buen día su nombre llegó a ser signo de que habíamos tomado conciencia de que sus libros recorrían la América del Sur con libertad, que parecía sangre agitada de nuestro agitado y único continente. Entonces fue que decidimos intentar conocer a fondo su creación, su obra, traducirla, estudiarla, redescubrirla de entre muchas otras, y esa es la historia que a menudo trae más lectores y que aún no acaba porque es costumbre nuestra la de no olvidar a los buenos amigos. Y Nikos Kazantzakis fue uno de ellos.

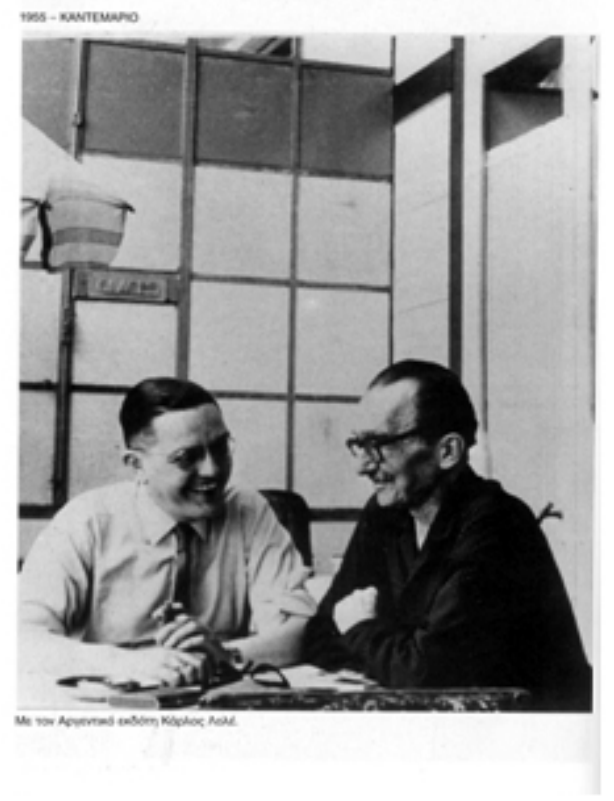




\section{Roberto Quiroz P.: Un escritor griego fuera de Europa \\ Bibliografía crítica}

Castillo Didier, Miguel. (1975). "Post Scriptum" a la Odisea de Nikos Kazantzakis. Barcelona: Editorial Planeta.

Castillo Didier, Miguel. (2006-2007). La Odisea en la Odisea. Estudios y ensayos sobre la Odisea de Kazantzakis. Santiago: Centro de Estudios Griegos

Bizantinos y Neohelénicos, Universidad de Chile.

Del Solar, Hernán. (1942). "Escaparate editorial chileno 1941". Concepción: Atenea, Tomo LXIX, 205.

García Gual, Carlos. (2000). "Introducción” a Homero, Odisea. Traducción de José M. Pabón. Madrid: Gredos.

Kazantzakis, Nikos. (1958). The Odyssey. A modern sequel. Traducción, Introducción, Notas, Apéndice, Sinopsis de Kimon Friar. New York: Simon and Schuster, $2^{\mathrm{a}}$.

Kazantzakis, Nikos. (1962). Del Monte Sinaí a la Isla de Venus. Traducción del francés Andrés Lupo Canaleta. Barcelona: Editorial Planeta, vol. II.

Kazantzakis, Nikos. (1975). Odisea. Traducción, Introducción, Notas, Glosario de Miguel Castillo Didier. Barcelona: Editorial Planeta.

Kazantzaki, N.-Eleni. (1974). Kazantzaki, el disidente. Nikos Kazantzaki visto a través de sus cartas, notas y textos inéditos. Barcelona: Planeta.

Lago, Tomás, (1934). "Los derechos de autor y el porvenir del libro chileno". Santiago: Anales Universidad de Chile, 14.

Lohlé, Carlos. (1986). Presencias y experiencias. Buenos Aires: Carlos Lohlé.

Quiroz, Roberto, (1997). Nikos Kazantzakis: su Cronología, Bibliografia Castellana e Iconografia poética. Santiago: Centro de Estudios Griegos Bizantinos y Neohelénicos, Universidad de Chile.

Quiroz, Roberto. (2003). Nikos Kazantzakis Impromptu filosófico: dimensiones de un poeta pensador. Santiago: Centro de Estudios Griegos Bizantinos y Neohelénicos, Universidad de Chile.

Ramos, Oscar. (1970). La Odisea: un itinerario humano. Bogotá: Instituto Caro y Cuervo.

Reboreda, S.(1996). “Odiseo, el héroe peculiar”, en J. Bermejo-Reboreda, S., Los origenes de la mitología griega. Madrid: Akal.

Subercaseaux, Bernardo. (2000). Historia del libro en Chile (Alma y cuerpo). Santiago: LOM Editores. 